\title{
The Neonatal Congenital Anomalies: Incidence and Risk Factors Before and After the war at Al-Thawrah Hospital- Sana'a,Yemen.
}

\author{
Fawz Mohammed Abol-Gaith ${ }^{1}$, Nada Ahmed Ismail ${ }^{2}$, Adel Ahmed Al-Mutawakel ${ }^{3}$ \\ 1. Assistant Professor, Department of Nursing, Faculty of Medicine and Health Sciences, Sana'a University, \\ Republic of Yemen. \\ 2. Assistant Professor, Department of Nursing, Faculty of Medicine and Health Sciences, Sana'a University, \\ Republic of Yemen. \\ 3. Assistant Professor, Department of Community Medicine, Faculty of Medicine and Health Sciences, Thamar \\ University, Republic of Yemen.
}

\begin{abstract}
Background: Congenital anomalies (CAs) are structural or functional abnormalities that occur during intrauterine life and can be identified prenatally, at birth or may be detected in infancy later. Aim: To compare the incidence and risk factors of neonatal congenital anomalies before and after war at Al-Thawrah Hospital, Sana'a, Yemen. Design: Retrospective cross-sectional study. Setting: The study was carried at Al-Thawrah Hospital - Sana'a, Yemen.Subjects: 112 CAs cases before war and 170CAs cases after war. Tool: Structural questionnaire with three parts, demographic data, mothers' data and neonates' data. Results: The incidence rate of CAs were approximately doubled after the war, the risk difference was 20.32 per 10,000/year. There was no significant difference between mortality rates $(\mathrm{P}>.05)$. There was a significant difference between the birth weights. $87.1 \%$ of mothers were lived close to airstrike. Most of the mothers had neither chronic nor acute diseases. $60.1 \%$ of mothers have not used medication and $89.4 \%$ of mothers did not expose to radiation. Conclusion: The incidence rate of CAs was markedly high after the war. The common risk factors such as the nutritional status of mothers and exposure to medications and radiation after the war were seemed to be neutral. Recommendation: Establish a committee for investigation about the environmental pollution that may cause CAs during the war.
\end{abstract}

\section{Keywords: Before and after War, Congenital Anomalies, Incidence, Neonate \& Risk Factors.}

\section{Introduction}

Congenital anomalies (CAs), fetal growth restriction and prematurity are the main causes of morbidity and mortality during childhood. (Mattison, 2010). The aetiologies of many developmental disorders are poorly understood; however, some risk factors have already been identified, such as environmental or occupational exposures, medications, smoking, the use of illicit drugs and alcohol; maternal diseases, such as pre-gestational diabetes mellitus, thyroid dysfunction; and congenital infections. (Almeida et al., 2016).

The growing literature indicates that environmental factors may cause genetic mutations and interact with genetic factors predisposing to birth defects. (Buczyńska \& Tarkowski, 2005). This increases concern about maternal and paternal environmental exposures, and natural or terrorist inflicted disasters on pregnancy outcome and developmental health. (Mattison, 2010)).

Adding to these concerns have been publications evaluating the capabilities of surveillance systems in the United States to identify emerging developmental diseases (Elliott et al., 2005), and information on human body burdens of an enlarging list of chemicals, many suspect as developmental hazards (CDC, 2009)

Every year an estimated 7.9 million children are born with a serious birth defect of genetic or partially genetic origin (Ndibazza et al., 2011) The proportion of neonatal mortality due to these defects increased from 3\% in 2008 to $4.4 \%$ in 2013 (Liu et al., 2015, Oestergaard et al., 2011) Unfortunately, more than $90 \%$ of congenital anomalies occur in low and middle income countries (Sitkin et al., 2015).

Congenital anomalies are part of a spectrum of adverse pregnancy outcome that associated with exposure to environmental pollution such as chemical substances in war or other exposure. This spectrum also include fetal death, early spontaneous abortion, low birth weight associated with prematurity or intrauterine growth retardation, and neurodevelopmental effects that can only be detected in later infancy and childhood. Environmental pollution during war or other exposure for chemical substances is a principal cause of congenital anomalies. Athrough pre-conceptional mutagenic action or postconceptional teratogenic action (Dolk \& Vrijheid, 2003). 
In Yemen, even if children are not the immediate casualties of the war. They are also hit the hardest by its indirect result. Women who became pregnant during period of war in Yemen have given birth in deplorable conditions as the pregnancy had occurred in difficulty conditions presented by no proper medical care, lack of proper food and water services, pollution of environment with war remains (chemical materials) in addition to devastated of country economy and increase of poverty among Yemeni population, all these factors leading to increase numbers of babies born with congenital anomalies in addition to that mothers had given birth of premature, malnourished and low birth weight babies.

The nurses could use the results of this study to realize the situation that Yemen pass-through. The nurses' have a great role in the prevention of the congenital anomalies. This role can be represented in the health education for the pregnant women about the risk factors that can lead to the malformation of the foetus. Also, the importance of the use of the folic acid, controlling of blood sugar and blood pressure during pregnancy, can be emphasized during the prenatal care. During the war, the nurse can highlight the hazards of the air pollutions from the war remains and educate the pregnant women about the effects of this pollution on their pregnancies and how they can avoid it.

\section{Significance of the study}

Yemen is considered as one of low income countries. Moreover, in the last years, Yemen suffers from an aggression that makes the environment polluted with war remains. Also, malnutrition in Yemeni mothers, poverty, unemployment and psychological factors are predisposing for congenital anomalies among neonate in Yemen. The aim of this is to compare the prevalence of congenital anomalies before and after the war on Yemen among neonate at Al-Thawrah Hospital-Sana'a.

\section{Aim of the study}

To compare the incidence and risk factors of neonatal congenital anomalies before and after war at ALThawrah Hospital - Sana'a, Yemen.

\section{Operational definitions}

Congenital Anomalies: Refers to an anomaly that affects a body part or physiologic function and is present at birth.

Neonate: Refers to infants in the first 28 days after birth, the term applied to premature, full term, and post-term.

Incidence: Individual in a population who have disease or health condition at percentage of the specific period usually expressed as a population. In this study refers to occurrence of C.A during the period of study in Al-Thawrah Hospital.

\section{Patients \& Method \\ Research design}

A retrospective, cross-sectional research was used to fit the nature of this study.

\section{Setting of the study}

The present study was conducted at Al-Thawrah Hospital- Sana'a. Al-Thawrah Hospital provides multi-specialist care and serves as a major referral center for hospitals within and outside Sana'a city including all the cities in Yemen.The Pediatric Intensive Care Unit (PICU), nursery and pediatric wards are included in the study. The Pediatric Intensive Care Unit (PICU) and nursery unit provides care for neonates delivered within and outside the hospital.

Subject

This study included 282 mothers with her neonates (during 28 days after delivery) during the period of $2013 \& 2014$ before war and the period of $2016 \&$ 2017 after war. They were selected randomly and divided into two groups. The control group was 112 mothers with her neonates from 20374 deliveries before war, while, the study group war 170 mothers with her neonates from 17904 deliveries after war.

\section{Inclusion criteria}

1. Full term baby $37-40$ weeks..

2. Born with one or more congenital anomalies.

3. Birth weight between $2.5-4 \mathrm{Kg}$.

Ixclusion criteria

1. Premature neonates.

2. Low birth weight.

3. Post maturity.

Study Tool

A structured questionnaire was constructed according to the literature review and current study objectives. It consists of three parts:

1)Demographic characteristics of mother: Age, level of education, occupation of mother, residence, family income, maternal habits.

2) Clinical data of mother: Consanguinity, blood group, frequency of pregnancy, history of abortion, type of delivery, gestational age, number of delivery, chronic maternal diseases, acute maternal illness during pregnancy, nutritional status during pregnancy, medication used during pregnancy, maternal exposure to radiation.

3) Neonate data: Date of birth, sex, order of children, time of diagnosis, complication at birth, outcome of birth defect, type of system effected, presence of anomaly in offspring, birth weight, newborn 
admitted nursery, history of twins, Complication of congenital anomalies, outcome of congenital anomalies.

\section{Validity and Reliability}

The questionnaire was reviewed by three experts in community health and statistics to prove its content validity. The modifications were done according their notes. The reliability was test by the Cronbach's alpha test which was 0.791 .

\section{Administrative approval}

A permission letter was taken from the administration of the faculty of Medicine and Health Science-Sana'a University to the administration of Al-Thawrah Hospital. The letter explain the objectives of the study and whom will be collected the data to give an access to the patients records.

\section{Ethical Consideration}

The information collected from the neonates' records were coded and strictly secured. Also, the anonymity was guaranteed for the information.

The data were collected from the neonates' records, so the consent were not taken from the neonates. Oral consent from neonates' families was taken when some data was missed and conduct them by phone. Also, the explanation of the study aim was done during the phone conversations.

\section{Pilot study}

Piloting was done to assure accuracy, consistency, and feasibility of the study. Also, to discover the difficulties that may face the researchers during the main study and overcome them. And to estimate the length of time needed to fill the structured questionnaire. According to the results of the pilot study the essential modifications were done. The pilot study was carried on $10 \%$ of the total number of the neonates.

\section{Method}

\section{Procedure}

The medical records were reviewed retrospectively over 4 years. These 4 years are divided as 2 years before war (2013 \& 2014) and 2 years after war (2016 \& 2017). After taking a permission form hospital's administration, the data were collected retrospectively by review the patients records by using a structured questionnaire. The missing data in the neonates records, were collected by conducted their families using a phone numbers that available in the neonates records. The family income was estimated according to the monthly income of them. The data about the mothers' nutritional status depend on the information that available in the records. Also, a pilot study was done.

\section{Statistical design}

Data collected were analysed using the SPSS version 21.The data were coded and double-checked.
Categorical variables were summarized using frequencies, ratios and proportions, along with the 95\% confidence interval. Continuous variables were summarized using mean and standard deviation. The incidence rate of CA was calculated as the proportion of neonates with $\mathrm{CA}$ among the total number of neonates admitted during the study period. Associations of neonatal characteristics and maternal socio-demographic factors with congenital anomalies were tested using the chi square statistic. The level of significance was set at $p<0.05$. 


\section{Results:}

Table (1): Distributed of cases according to the socio-demographic data of the neonatal mothers before and after war.

\begin{tabular}{|c|c|c|c|c|c|}
\hline \multicolumn{2}{|c|}{ Socio - demographic data } & \multicolumn{2}{|c|}{ Before } & \multicolumn{2}{|c|}{ After } \\
\hline & & $\mathrm{N}$ & $\%$ & $\mathrm{~N}$ & $\%$ \\
\hline \multirow[t]{6}{*}{ Age } & $<18$ & 0 & 0.0 & 2 & 1.2 \\
\hline & $18-25$ yrs & 9 & 8.0 & 56 & 32.9 \\
\hline & $26-33$ yrs & 98 & 87.5 & 75 & 44.1 \\
\hline & $34-41$ yrs & 5 & 4.5 & 36 & 21.2 \\
\hline & $42+\quad$ yrs & 0 & 0.0 & 1 & 0.6 \\
\hline & Total & 112 & 100 & 170 & 100 \\
\hline \multirow[t]{7}{*}{ Education } & Illiterate & 4 & 3.6 & 27 & 15.9 \\
\hline & Literate & 2 & 1.8 & 8 & 4.7 \\
\hline & Primary education & 8 & 7.1 & 53 & 31.2 \\
\hline & Secondary school & 5 & 4.5 & 28 & 16.5 \\
\hline & University and above & 2 & 1.8 & 18 & 10.6 \\
\hline & Missing & 91 & 81.3 & 36 & 21.2 \\
\hline & Total & 112 & 100.0 & 170 & 100.0 \\
\hline \multirow[t]{4}{*}{ Occupation } & Employee & 0 & 0.0 & 13 & 7.6 \\
\hline & Housewife & 20 & 17.9 & 121 & 71.2 \\
\hline & Missing & 92 & 82.1 & 36 & 21.2 \\
\hline & Total & 112 & 100.0 & 170 & 100.0 \\
\hline \multirow[t]{4}{*}{ Residence } & near air strike & 27 & 24.1 & 148 & 87.1 \\
\hline & Far from air strike & 5 & 4.5 & 10 & 5.9 \\
\hline & Missing & 80 & 71.4 & 12 & 7.1 \\
\hline & Total & 112 & 100.0 & 170 & 100.0 \\
\hline \multirow[t]{5}{*}{ Family income } & Poor & 0 & 0 & 8 & 4.7 \\
\hline & moderate & 22 & 19.6 & 101 & 59.4 \\
\hline & Rich & 5 & 4.5 & 29 & 17.1 \\
\hline & Missing & 85 & 75.9 & 32 & 18.8 \\
\hline & Total & 112 & 100.0 & 170 & 100.0 \\
\hline
\end{tabular}
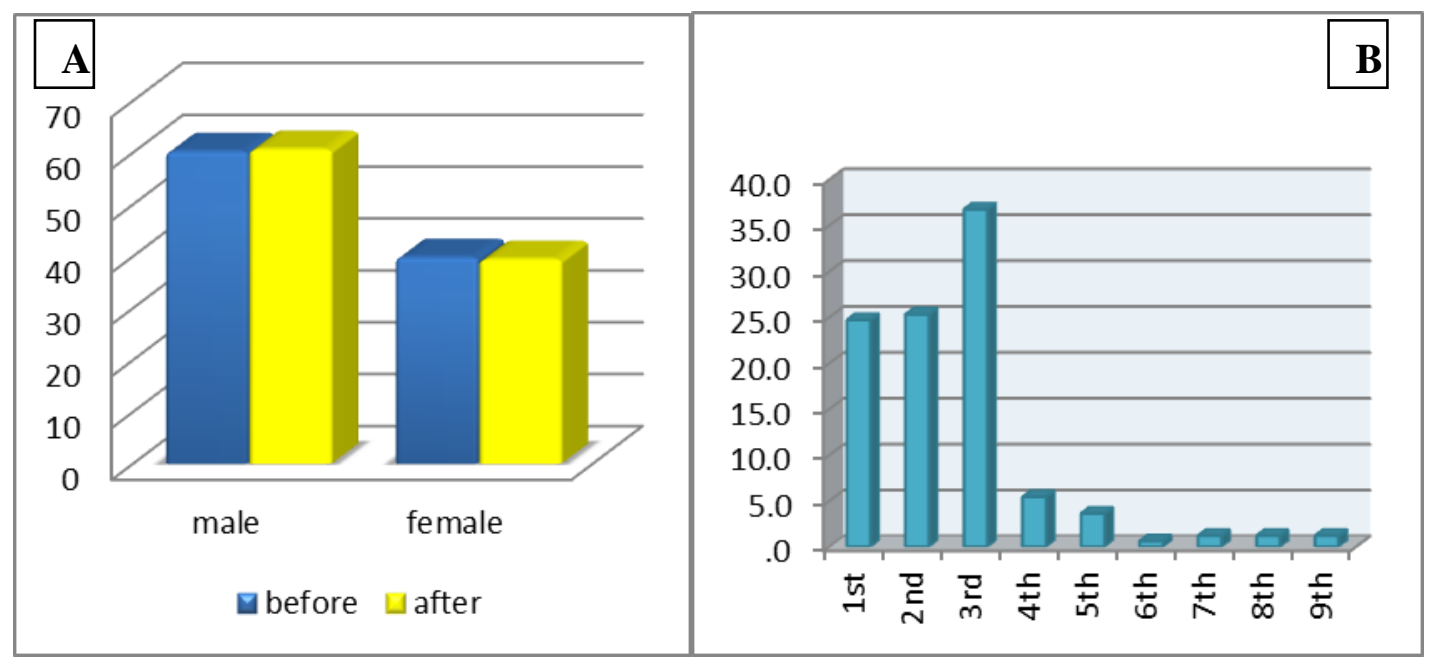

Figure (1): Distributed of neonates before and after war according to: (A) Sex and (B) order in the family. 
Table (2): Distributed of case before and after war according to the birth weight

\begin{tabular}{|c|c|c|c|c|c|}
\hline & & $\mathrm{N}$ & Mean & SD & $\mathrm{P}-$ value \\
\hline \multirow[t]{2}{*}{ Birth weight } & before & 97 & 2.6133 & 0.729 & \multirow[t]{2}{*}{0.016} \\
\hline & After & 143 & 2.3852 & 0.706 & \\
\hline
\end{tabular}

Table (3): Distributed of case before and after war according to the type of congenital anomalies.

\begin{tabular}{|c|c|c|c|c|c|c|}
\hline \multicolumn{2}{|c|}{} & $\begin{array}{c}\text { Hydrocephalus N } \\
(\%)\end{array}$ & $\begin{array}{c}\text { oesophageal } \\
\text { atresia } \\
\mathbf{N}(\%)\end{array}$ & $\begin{array}{c}\text { Cleft lip and } \\
\text { palate N (\%) }\end{array}$ & $\begin{array}{c}\text { Congenital } \\
\text { heart disease N } \\
(\%)\end{array}$ & $\begin{array}{c}\text { imperforate } \\
\text { anus } \\
\mathbf{N}(\%)\end{array}$ \\
\hline \multirow{2}{*}{ Before } & & $17(15)$ & $10(8.9)$ & $7(6.2)$ & $5(4.4)$ & $4(3.6)$ \\
\hline \multirow{2}{*}{ After } & & $24(14.1)$ & $15(8.9)$ & $7(4.1)$ & $11(6.5)$ & $13(7.7)$ \\
\cline { 2 - 7 } & Total & $41(14.1)$ & $25(8.65)$ & $14(4.8)$ & $16(5.53)$ & $17(5.8)$ \\
\hline
\end{tabular}

Table (4): Distributed of case before and after war according to the system included.

\begin{tabular}{|l|c|c|c|c|c|c|}
\hline \multicolumn{2}{|c|}{} & $\begin{array}{c}\text { CNS } \\
\text { N }\end{array}$ & $\begin{array}{c}\text { CVS } \\
\mathbf{N}(\boldsymbol{\%})\end{array}$ & $\begin{array}{c}\text { MuscSkeletal } \\
\mathbf{N}(\boldsymbol{\%})\end{array}$ & $\begin{array}{c}\text { GentUrinary } \\
\mathbf{N}(\boldsymbol{\%})\end{array}$ & $\begin{array}{c}\text { GIT } \\
\mathbf{N}(\boldsymbol{\%})\end{array}$ \\
\hline \multirow{3}{*}{ Before } & Yes & $29(25.9)$ & $5(4.5)$ & $2(1.8)$ & $4(3.6)$ & $16(14.3)$ \\
\cline { 2 - 7 } & No & $81(72.3)$ & $105(93.8)$ & $110(98.2)$ & $106(94.6)$ & $94(83.9)$ \\
\cline { 2 - 7 } & missing & $2(1.8)$ & $2(1.8)$ & 0 & $2(1.8)$ & $2(1.8)$ \\
\cline { 2 - 8 } & Total & $112(100)$ & $112(100)$ & $112(100)$ & $112(100)$ & $112(100)$ \\
\hline \multirow{5}{*}{ After } & Yes & $42(24.7)$ & $15(8.8)$ & $5(2.9)$ & $30(17.6)$ & $35(20.6)$ \\
\cline { 2 - 7 } & No & $128(75.3)$ & $155(91.2)$ & $165(97.1)$ & $140(82.4)$ & $135(79.4)$ \\
\cline { 2 - 7 } & missing & 0 & 0 & 0 & 0 & 0 \\
\cline { 2 - 7 } & Total & $170(100)$ & $170(100)$ & $170(100)$ & $170(100)$ & $170(100)$ \\
\hline
\end{tabular}

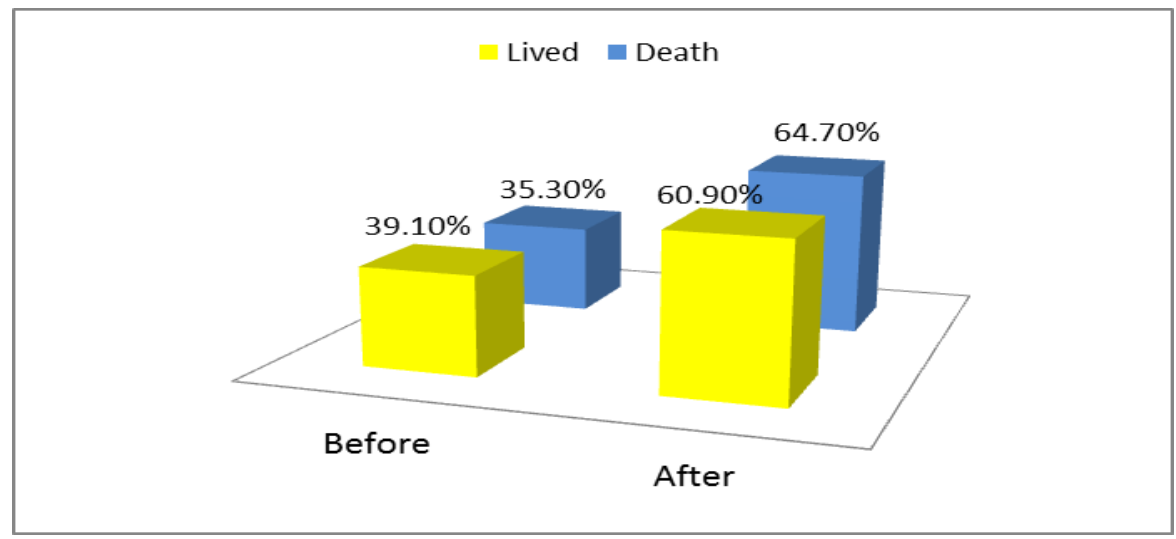

Figure (2): Distributed of case before and after war according to the mortality rate.

Table (5): The Prevalence Rate of congenital Anomalies before and after war.

\begin{tabular}{|c|c|c|c|c|}
\hline Year & $\begin{array}{c}\text { Total No. of } \\
\text { delivery }\end{array}$ & CA cases & $\begin{array}{c}\text { Incidence Rate } \\
\text { Per 10,000 }\end{array}$ & $\begin{array}{c}\text { Incidence Rate } \\
\text { Per 10,000-Year }\end{array}$ \\
\hline 2013 & 9,894 & 53 & 53.56 & \\
\hline 2014 & 10,480 & 59 & 56.29 & \\
\hline Total & 20,374 & 112 & 54.92 & 27.46 \\
\hline 2016 & 9,727 & 86 & 88.41 & \\
\hline 2017 & 8,177 & 84 & 102.72 & 47.78 \\
\hline Total & 17,904 & 170 & 95.56 & \\
\hline
\end{tabular}


Table (6): Frequencies and percentages of cases according to the factors that confounding the occurrence of Cas After War.

\begin{tabular}{|c|c|c|c|}
\hline & & $\mathbf{N}$ & $\%$ \\
\hline \multirow[t]{3}{*}{ Address } & Near air strike & 148 & 93.6 \\
\hline & Far from strike & 10 & 6.3 \\
\hline & Total & 158 & 100 \\
\hline \multirow[t]{4}{*}{ Family income } & poor & 8 & 5.8 \\
\hline & moderate & 101 & 73.2 \\
\hline & rich & 29 & 21 \\
\hline & Total & 138 & 100 \\
\hline \multirow[t]{4}{*}{ Mothers' Nutritional status } & Good & 109 & 79 \\
\hline & Anemic & 13 & 9.4 \\
\hline & Malnourished & 26 & 11.6 \\
\hline & Total & 138 & 100 \\
\hline \multirow[t]{3}{*}{ Consanguinity } & Yes & 43 & 31.6 \\
\hline & No & 93 & 68.4 \\
\hline & Total & 136 & 100 \\
\hline \multirow[t]{6}{*}{ Chronic disease } & Hypertension & 12 & 9.2 \\
\hline & DM & 11 & 8.4 \\
\hline & Anemia & 9 & 6.9 \\
\hline & Epilepsy & 2 & 1.5 \\
\hline & None & 96 & 73.8 \\
\hline & Total & 130 & 100.0 \\
\hline \multirow[t]{5}{*}{ Acute disease during pregnancy } & Gestational DM & 1 & 0.7 \\
\hline & Pre-eclampsia & 9 & 6.9 \\
\hline & Eclampsia & 2 & 1.5 \\
\hline & None & 118 & 90.7 \\
\hline & Total & 130 & 100 \\
\hline \multirow{5}{*}{ Medication used during pregnancy } & Vitamin & 30 & 22.7 \\
\hline & Folic acid & 38 & 28.7 \\
\hline & Anti HTN & 9 & 6.8 \\
\hline & none & 55 & 41.6 \\
\hline & Total & 132 & 100 \\
\hline \multirow[t]{4}{*}{ Radiation Exposure } & X-ray & 5 & 3.6 \\
\hline & $\mathrm{CT}$ & 1 & 0.7 \\
\hline & None & 132 & 95.7 \\
\hline & Total & 138 & 100 \\
\hline
\end{tabular}

A total number of 282 neonates of CAs were recorded during the study period. 112 neonates were before war and 170 cases after the war.

Table (1): This table shows the distribution of some demographic data of the mothers such as age, education, occupation, family income and residence. The dominant mother's ages were between 26 and 33 years old. Most of the mothers were housewives with primary education. Most of the families were moderate income and lived near the air strike. $60 \%$ of the neonates were male before and after war (Figure 1A) and $35 \%$ were the third child in their families (Figure 1B).
Table (2): It was illustrated that there were a significant difference between the neonate before and after war according to the birth weight ( $\mathrm{P}$ value=.016). The neonates have lower birth weight after war.

The most common type of the CAs was hydrocephalus both before and after war. The second commonest type after war was oesophageal atresia. Congenital heart disease, cleft lip and palate; and imperforate anus were also common before and after war. New types of CAs have appeared after war as respiratory tract atresia, meningocele and acephaly Table (3): The central nervous system (CNS) is the most body system that involved in the CAs before 
and after war followed by gastrointestinal tract (GIT) (Table 4).

Fig (2): It was illustrated that there was no significant difference between mortality rate before and after war (P-value> .05) The mortality rate were $35.3 \%$ and $39.1 \%$ before and after war, respectively.

Table (5): This table shows the total number of the deliveries in Al-Thawrah Hospital during 2013 and 2014 (before war) was 20374 deliveries and the CAs cases were 112 cases with incidence rate 27.46 per 10,000-year. While, after war, the total number of the deliveries was17, 904 (2016 and 2017) and the CAs cases were 170 cases with incidence rate 47.78 per 10,000-year.

Table (6): It was revealed that the most of the mothers after the war have their residence in the areas near the air strike in Sana'a city 93.6\%. Also, $79 \%$ of mothers have a good nutritional status, $73.8 \%$ did not have any chronic diseases and $90.7 \%$ did not have any acute diseases during pregnancy. In relation to the medication used during the pregnancy, $41.6 \%$ of mothers did not use any medications, while, $28.7 \%$ used folic acid. Most of the mothers were not exposed to the radiations as X-ray or CT scan.

\section{Discussion}

The current study reveals that the incidence rate of the CAs was increased to the double after war in Yemen. It was 27.46 per 10,000/ year before war and increased to the 47.78 per 10,000 / year after war. In Nigeria, in 2019 the prevalence of CAs was $6.3 \%$ in the normal situation (no war) while it was $11.1 \%$ in 1994. (Adeyemo et al., 1994; Ajao \& Adeoye, 2019) In Lebanon, the incidence rate of CA is $2.4 \%$. (Rizk, 2014) Also, in Brazil, the prevalence of CAs was 2.4\%. (Almeida et al., 2016) In Gaza, Naim et al. (2012) have reported the prevalence as 4 per 1000 in one hospital. While, Abed et al., (2014) compare the prevalence rate of CAs between 2006 and 2010, and they found that the prevalence increased from 39.5 per 1000 in 2006 to 65 per 1000 in 2010. It is concluded that the CAs cases in Al-Thawrah Hospital was within the range with other countries, but they precede this range after the war.

According mother's age is considered as one of the common factors and causes that lead to CAs $(<18$ $\&>35)$. It is noted that in the current study most of the mothers' age were between $18-35$ years old. This comes in the context with study done by some researchers which they reported that the most mother have age between 21 - 35 years old and the mean was 28.74. (Ajao \& Adeoye, 2019, Rizk et al., 2014).

In the other hand, this study shows that the most of the residences of the neonates' families were near the airstrikes zones in Sana'a city (87.1\%). This high percentage supports the assumption of the great influence of war on the incidence of CAs.

A study done in São Paulo city, they report the female gender as a protective factor $(\mathrm{OR}=0.78)$ and the multiple pregnancies as a risk factor $(\mathrm{OR}=1.28)$.

(Cosme et al., 2017) Another study was done showed that males were more affected with CAs than females (63\% versus 37\%). (Abdou et al., 2019)

In comparing the birth weight of the neonates before and after war it was found that the mean and the SD before war is higher than after war with $\mathrm{P}$-value = 0.016. This factor (low birth weight) may be considered as a confounding factor to prove the effect of war on the occurrence of CAs. Although AlHadithi et al., ( 2012) and Almeida et al., (2016) considered the low birth weight as one of the adverse outcome of the CAs. Rizk et al., (2014) reported that the association between the low birth weight and CAs are statistical significant.

In the current study the mortality rate were $35.3 \%$ and $39.1 \%$ before and after war, respectively. (Pvalue $>0.05)$. This rate is higher than of that found by Al-Hadithi et al., (2012) at Fallujah General Hospital which was $24 \%$ which whom died within 7 days. (Al-Hadithi et al., 2012) In the other hand, the mortality rate that reported by Rizk et al. (2012) was the least $(14 \%)$ but it is noted that this result was in normal conditions (no war) in Lebanon. (Rizk et al., 2014)

The present study reports that the order of the occurrence of the CAs according to the type was hydrocephalus, oesophageal atresia. Congenital heart disease, Diabetes Mellitus, cleft lip and palateand imperforate anus. New types of CAs have appeared after war as respiratory tract atresia, meningocele and acephaly. While, the most body system that involved in the CAs were the CNS and GIT before and after war. These findings are consistent with previous studies which also found that the CNS are the most common anomalies. (Himmetoglu et al., 1996; Dastgiri, et al., 2007; Singh \& Gupta, 2009; Dolket al., 2010, Al-Hadithi et al., 2012; Almeida et al., 2016) The musculoskeletal system was the second most CAs in Iraq followed by GIT. (Al-Hadithi et al., 2012) In a study that carried out in USA about the relationship between the environmental exposure and the birth defect. It is revealed that the cardiovascular diseases (CVD) are the most common CAs. (Mattison, 2010) The recent study in Nigeria, they found that the most common CAs is the urinarygenital system and musculoskeletal system followed by CNS, CVS and GIT. (Ajao \& Adeoye, 2019)

The relationship between the CAs in the CNS and the use of folic acid was not statistical significant in the 
current study. A study done by Almeida et al., (2016) found that $68 \%$ of the mothers that have CAs neonate in the CNS were not taken folic acid during pregnancy. Other studies indicate the effective prevention of fetal CAs with the regular folic acid supplementation mainly CNS defects. (Dolk et al, 2010, Youngblood et al., 2013)

The causes of the CAs have a wide variety, so the occurrence of the CAs could be confounding with other factors such as nutritional status of the mothers, (Yoon et al., 2001, Mattison, 2010, Taboo, 2012, Al-Hadithi et al., 2012, Youngblood et al., 2013, Devakumar et al., 2014, Almeida et al., 2016, Abdou et al., 2019) Consanguinity of the parents, (Adeyemo et al., 1994; Naim et al., 2012; Taboo, 2012, Rizk et al., 2014, Abdou et al., 2019), exposure to the radiation,( Mattison, 2010, AlHadithi et al., 2012, Taboo, 2012, Devakumar et al., 2014, Almeida et al., 2016, Abdou et al., 2019) taking medications during pregnancy. (Adeyemo et al., 1997, Yoon et al., 2001, Mattison, 2010, Taboo, 2012, Almeida et al., 2016, Abdou et al., 2019) and chronic disease. (Adeyemo A et al., 1997, Yazbeck et al., 2009, Mattison, 2010, Devakumar et al., 2014, Almeida et al., 2016, Abdou et al., 2019) of the mothers or acute disease (Adeyemo et al., 1994, Devakumar et al., 2014, Almeida et al., 2016., Abdou et al., 2019) during pregnancy.

In this study, these factors were taking in account. After war $79 \%$ of the mothers have a good nutritional status, $68.4 \%$ of parents were not relatives, $68.4 \%$ of mothers did not use any medications during pregnancy and $95.7 \%$ did not expose to the any radiation as X-rays or CT scan. Most of the mothers did not have chronic diseases $(73.8 \%)$ nor acute illness during pregnancy $(90.7 \%)$. It is clear that the common risk factors of CAs are not found in this study and impact of war on the occurrence of CAs is evidently great.

\section{Conclusion \& Recommendations}

Based in the results it can be concluded that:

Most of the mothers were aged between $18-25$ years-old, and they were house-wives with basic education. Most of the neonates were male with normal delivery. The incidence rate of congenital anomalies was markedly high after war. New types of CA were appeared after war as respiratory tract atresia, meningocele, and acephaly. The common and known risk factors such as exposure to radiation and medication used, seemed to be neutral in this study.

\section{Recommendation}

Based on the results the following points are recommended:

- Establish a committee for investigation about the environmental pollution that may cause congenital anomalies during war.

- The administrations of governmental and private hospital should be kept a good archive for the documentation of any CA cases that detected in the hospitals.

- Provide and develop programs for health education about congenital anomalies and their risk factors.

- Further research must be done nationwide to reveal the real association between war and congenital anomalies.

\section{References}

1. Abdou, M., Sherif, A., Wahdan, I., \& Ashour, K., (2019): Pattern and risk factors of congenital anomalies in a pediatric university hospital, Alexandria, Egypt. J Egypt Public Health Assoc, 94(1), 3. doi:10.1186/s42506018-0004-3

2. Abed, Y., Al Barqouni, N., Naim, A., \& Manduca, P., (2014): Comparative study of major congenital birth defects in children of 0-2 years of age in the Gaza Strip, Palestine.

3. Adeyemo, A., Okolo, C., \& Omotade, O., (1994): Major congenital malformations among paediatric admissions at University College Hospital, Ibadan, Nigeria. Annals of tropical paediatrics, 14(1), 75-79.

4. Ajao, A., \& Adeoye, I., (2019): Prevalence, risk factors and outcome of congenital anomalies among neonatal admissions in OGBOMOSO, Nigeria. BMC Pediatr, 19(1), 88. doi:10.1186/s12887-019-1471-1

5. Al-Hadithi, T., Al-Diwan, J., Saleh, A., \& Shabila, N., (2012): Birth defects in Iraq and the plausibility of environmental exposure: A review. Confl Health, 6(1), 3 doi:10.1186/1752-1505-6-3

6. Almeida, L., Júnior, E., Crott, G., Okido, M., Berezowski, A., \& Duarte, G., (2016): Epidemiological risk factors and perinatal outcomes of congenital anomalies. Rev Bras Ginecol Obstet 38(07), 348-355.

7. Buczyńska \& Tarkowski (2005): Environmental exposure and birth outcomes. 18, 225-232.

8. Cosme, H., Lima, L., \& Barbosa, L., (2017): Prevalência De Anomalias Congênitas E Fatores Associados Em Recém-Nascidos Do Município 
De São Paulo No Período De 2010 A 2014. Revista Paulista de Pediatria, 35, 33-38. Retrieved from http://www.scielo.br/scielo.php?script=sci_artte xt\&pid=S0103-05822017000100033\&nrm=iso

9. Dastgiri, S., Imani, S., Kalankesh, L., Barzegar, M., \& Heidarzadeh, M., (2007): Congenital anomalies in Iran: a cross-sectional study on 1574 cases in the North-West of country. Child: care, health and development, 33(3), 257-261.

10. Devakumar, D., Birch, M., Osrin, D., Sondorp, E., \& Wells, J., (2014): The intergenerational effects of war on the health of children. BMC medicine, 12(1), 57.

11. Dolk, H., Loane, M., \& Garne, E., (2010): The prevalence of congenital anomalies in Europe. Rare diseases epidemiology, 349-364.

12. Dolk, H., \& Vrijheid, M., (2003): The impact of environmental pollution on congenital anomalies. British Medical Bulletin, 68(1), 2545.

13. Elliott, K., Segal, L., Juliano, C., Mandel, J., \& Hearne, S., (2005): Birth Defects and Developmental Disabilities: The Search for Causes and Cures. Issue Report [serial on the Internet], Available from: www.healthyamericans.org.

14. CDC N., (2009): Human Exposure to Environmental Chemicals Fourth Report. Atlanta Georga: Department of Health and Human Services, Centers for Disease Control and Prevention.

15. Himmetoglu, O., Tiras, M., Gursoy, R., Karabacak, O., Sahin, I., \& Onan, A., (1996): The incidence of congenital malformations in a Turkish population. International Journal of Gynecology \& Obstetrics, 55(2), 117-121.

16. Liu, L., Oza, S., Hogan, D., Perin, J., Rudan, I., Lawn, J., Black, R., (2015): Global, regional, and national causes of child mortality in 2000-13, with projections to inform post2015 priorities: an updated systematic analysis. The Lancet, 385(9966), 430-440.

17. Mattison, D., (2010): Environmental exposures and development. Curr Opin Pediatr 22(2), 208.

18. Naim, A., Al Dalies, H., El Balawi, M., Salem, E., Al Meziny, K., Al Shawwa, R., Manduca, P., (2012): Birth defects in Gaza: prevalence, types, familiarity and correlation with environmental factors. Int J Environ Res Public
Health, $\quad 9(5)$, doi:10.3390/ijerph9051732

$1732-1747$

19. Ndibazza, J., Lule, S., Nampijja, M., Mpairwe, H., Oduru, G., Kiggundu, M., Elliott, A., (2011): A Description of Congenital Anomalies Among Infants in Entebbe, Uganda. Birth defects research. Part A, Clinical and molecular teratology, 91, 857-861. doi:10.1002/bdra.20838

20. Oestergaard, M., Inoue, M., Yoshida, S., Mahanani, W., Gore, F., \& Cousens, S., (2011): Neonatal Mortality Levels for 193 Countries in 2009 with Trends since 1990: A Systematic Analysis of Progress, Projections, and Priorities. PLOS Medicine, 8(8), e1001080. doi:10.1371/journal.pmed.1001080

21. Rizk, F., Salameh, P., \& Hamadé, A., (2014): Congenital anomalies: prevalence and risk factors. Universal Journal of Public Health, 2(2), 58-63.

22. Singh, A., \& Gupta, R., (2009): Pattern of Congenital Anomalies in Newborn: A Hospital Based Prospective Study. JK science, 11(1).

23. Sitkin, N., Ozgediz, D., Donkor, P., \& Farmer, D., (2015): Congenital anomalies in low-and middle-income countries: the unborn child of global surgery. World journal of surgery, 39(1), 36-40.

24. Taboo, Z., (2012): Prevalence and risk factors for congenital anomalies in Mosul city. Iraqi Academic Scientific Journal, 11(4), 458-470.

25. Yazbeck, C., Thiebaugeorges, O., Moreau, T., Goua, V., Debotte, G., Sahuquillo, J., Slama, R., (2009): Maternal blood lead levels and the risk of pregnancy-induced hypertension: the EDEN cohort study. Environmental health perspectives, 117(10), 1526-1530.

26. Yoon, P., Rasmussen, S., Lynberg, M., Moore, C., Anderka, M., Carmichael, S., Romitti, P., (2001): The National Birth Defects Prevention Study. Public health reports, 116(Suppl 1), 32.

27. Youngblood, M., Williamson, R., Bell, K., Johnson, Q., Kancherla, V., \& Oakley Jr, G., (2013): 2012 Update on global prevention of folic acid-preventable spina bifida and anencephaly. Birth Defects Research Part A: Clinical and Molecular Teratology, 97(10), 658663. 